\title{
Diagnosis and treatment of superficial esophageal cancer
}

\author{
Maximilien Barret, Frédéric Prat \\ Cochin Hospital, Paris, France
}

\section{Abstract}

\section{Introduction}

Esophageal cancer is the eighth most common cancer and the sixth most common cause of cancer death, with estimations of 456,000 new cases and 400,000 deaths in 2012 [1]. Squamous cell carcinoma (SCC) is the most frequent histological subtype because of its high prevalence in Asia, with up to $95 \%$ of cases of esophageal neoplasia in China [2], and persistent alcohol and tobacco consumption in Western countries [3]. In America and Northern Europe, however, esophageal adenocarcinoma (EAC) arising on Barrett's esophagus has recently become the most prevalent type of esophageal cancer [4,5]. Upper gastrointestinal endoscopy screening programs in Asia and surveillance protocols for Barrett's esophagus have allowed a greater proportion of early stage, T1-so-called "superficial"

Department of Gastroenterology and Digestive Oncology, Cochin Hospital, Paris, France

Conflict of interest: None

Correspondence to: Maximilien Barret, MD, PhD, Department of Gastroenterology and Digestive Oncology, Cochin Hospital, 27 rue du Faubourg St Jacques, 75014 Paris, France, e-mail: maximilien.barret@ aphp.fr

Received 10 January 2018; accepted 29 January 2018; published online 15 March 2018

DOI: https://doi.org/10.20524/aog.2018.0252 or "early" esophageal cancers-to be diagnosed. Mucosal (T1a) cancers include high-grade dysplasia (HGD), or in situ carcinoma (T1am1), and tumors infiltrating the lamina propria (T1am2) or the muscularis mucosae (T1am3). Submucosal cancers (T1b) can be classified as T1bsm 1, 2 or 3, depending on the invasion of the upper, middle, or deepest third of the submucosa on surgical specimens [6,7], or as superficial submucosal invasion (less than $200 \mu \mathrm{m}$ from the muscularis mucosae for SCC and less than $500 \mu \mathrm{m}$ for EAC) [8]. All T1 lesions are technically amenable to endoscopic resection (ER), but two caveats should immediately be raised: first, the risk of severe, refractory esophageal stricture following resections exceeding three fourths of the circumference [9], requiring repeated dilatations with a significant risk of perforation [10], has to be taken into account before performing extensive $\mathrm{ER}$, given the lack of efficient options to prevent esophageal stricture [11]. Second, the risk of lymph-node metastases has to be assessed based on the resected specimen to determine whether an ER has been curative or not. Esophagectomy, which remains a standard treatment for esophageal neoplasms, should now be restricted to lesions extending to the muscularis propria (T2 and over) and to superficial lesions bearing the highest risk of lymph-node metastases. Indeed, ER has proven equally effective in terms of oncological outcomes, with no procedurerelated mortality, a reduced morbidity, and a preserved quality of life $[12,13]$. Therefore, endoscopy is currently the cornerstone of the management of superficial esophageal 
cancer, allowing for screening, diagnosis, treatment- and follow up in most cases.

\section{Diagnostic workup}

\section{Endoscopy}

The vast majority of esophageal neoplasms are diagnosed at an advanced stage, in which the endoscopist encounters an irregular esophageal stenosis or tissular bud with an ulcerated surface and takes biopsies for histological documentation and therapeutic decision-making. The detection and characterization of superficial neoplasia can be challenging, since lesions typically appear as subtle and flat, Paris 0-IIb type. High-definition white-light endoscopy is a minimal requirement [8], and is usually associated with ancillary techniques such as dyes or so called virtual chromoendoscopy. Other prerequisites are the involvement of an experienced endoscopist and enough time for inspection of the mucosa. Noticeably, Gupta et al showed that a 1-min inspection time per longitudinal centimeter of Barrett's esophagus was associated with a higher rate of neoplasia detection [14]. The description of the lesions should include their size, Paris classification type, extension over the esophageal circumference and precise location (e.g., 5 o'clock) and distance from the dental arcade. The extent of the Barrett's esophagus should be reported using the Prague classification [15], which reports the circumferential (C) and the maximal extent (M) of the Barrett's segment, measured from the upper end of the gastric folds.

For the detection and delineation of SCC or squamous dysplasia, Lugol staining has long been the gold standard, with a per-lesion sensitivity of $88 \%$. Narrow-band imaging (NBI; Olympus, Tokyo) is a virtual chromoendoscopy technique that has shown sensitivity comparable to that of Lugol, and a superior specificity of $82 \%$ vs. $37 \%$ [16]. Indeed, cicatricial or parakeratotic lesions may appear as Lugol-negative and therefore suspicious, while NBI will show a benign pattern of the intrapapillary capillary loops (IPCL). Since there is no such feature as a pit pattern in the squamous epithelium, the microvascular pattern of the IPCL can be used to predict the degree of malignancy and invasiveness of the lesion [17]. A classification developed by Inoue et al subdivides the IPCL into 5 types, with type $\mathrm{V}$ (neoplastic) being subdivided into 4 subtypes: the last one, with neovessel formation, suggests deep submucosal infiltration, proscribing ER.

For the detection and characterization of Barrett'sassociated neoplasia, chromoendoscopy using methylene blue or indigo carmine has not proven useful $[18,19]$. Acetic acid spraying can be used to improve the visualization of mucosal irregularities in the columnar epithelium. Large studies have reported conflicting results on acetic acid over high definition white light endoscopy alone [20,21], and crossover studies are still lacking. Virtual chromoendoscopy techniques can rely on light filters, such as NBI or Blue Laser Imaging (Fujifilm, Tokyo), or post-processing techniques such as i-Scan, (Pentax, Tokyo) or Fujinon Intelligent Chromoendoscopy, also termed
FICE (Fujifilm, Tokyo). The most widely studied system is NBI, several studies concurring on the fact that irregular vascular and mucosal features are associated with early neoplasia [21-23], with $96 \%$ sensitivity and $94 \%$ specificity for the diagnosis of HGD. Although NBI provides a more detailed inspection of the mucosa than white-light endoscopy, clinical studies have not clearly demonstrated a benefit in terms of detection of Barrett's neoplasia. Most experts, however, do use NBI and virtual chromoendoscopy techniques for the characterization and delineation of early neoplastic lesions before resection [8]. It should be noted that low-grade dysplasia (LGD), already a challenging diagnosis for histopathologists, cannot be reliably distinguished endoscopically from non-dysplastic intestinal metaplasia or HGD.

After careful inspection, all visible abnormalities should be considered as malignant until proven otherwise and sampled in separate vials_-or resected right away. Two to three biopsies are usually sufficient, since biopsy sampling may induce submucosal fibrosis and hamper ER. However, discrepancies between endoscopic biopsies and resection specimens occur in about a third of cases, and en bloc ER should remain the gold standard for the diagnosis [8].

\section{Endoscopic ultrasound (EUS)}

The role of EUS in the initial staging of esophageal neoplasia remains controversial. A recent meta-analysis found high sensitivity and specificity of EUS for the diagnosis of T1a lesions of 0.85 (95\% confidence interval [CI] 0.82-0.88) and 0.87 (95\%CI $0.84-0.90$ ), respectively [24], but about $80 \%$ of the patients were investigated with an EUS miniprobe, unavailable in most centers. Conventional EUS probes do allow for an accurate differentiation between $\mathrm{T} 1$ and $\mathrm{T} 2$ stages, but this is generally not clinically relevant, since T2 lesions can usually be recognized endoscopically as a protruding type, with ulcerated features, large neovessels, and limited motility with esophageal peristalsis. However, EUS is able to detect regional lymph nodes with a sensitivity of $76 \%$ and a specificity of $72 \%$ [25], significantly better than computed tomography (CT) scan [26]. EUS-guided fine-needle aspiration can then increase the diagnostic accuracy of the $\mathrm{N}$-staging to $90 \%$ in advanced carcinomas [27]. However, in a retrospective analysis of 131 patients with early Barrett's neoplasia, Pouw et al showed that EUS alone never impacted treatment policy [28]. Finally, EUS is not routinely recommended in the workup of all early esophageal cancers [8]: the guidelines of the European Society of Gastrointestinal Endoscopy (ESGE) suggest limiting its use to high-risk lesions, in addition to CT scanning and positron emission tomography-CT.

\section{Advanced endoscopic techniques}

Advanced diagnostic endoscopic techniques, such as autofluorescence imaging, confocal laser endomicroscopy or optical coherence tomography, have been widely studied, 
mainly for the detection of Barrett's neoplasia. Autofluorescence imaging has failed to prove a significant improvement in the detection of early neoplasia [29]. The development of probebased confocal laser endomicroscopy is limited by its high cost and low sensitivity [30]. Optical coherence tomography is a promising tool for scanning the entire Barrett's mucosa; however, it is not yet ready for implementation in clinical practice [31]. Currently, no advanced endoscopic imaging technique is recommended, and targeted biopsies or resection of any visible lesion are advisable, in addition to random quadrantic biopsies in the case of Barrett's esophagus, according to the Seattle protocol [32].

\section{Endoscopic management of SCC}

\section{ER}

Endoscopic mucosal resection (EMR) has been widely studied since the 1990s for the treatment of early SCC. EMR can be conducted using submucosal injection, an oblique cap and an asymmetric resection snare [33], or a modified multiband ligator device allowing the passage of an electrosurgical snare [34]. The latter technique has proven as effective as the first, but is cheaper and faster, with a complication rate lower than the $1-2 \%$ perforation rate usually observed with capEMR [35]. All studies report consistent data, with en bloc resection rates ranging from $20-53 \%$, and local recurrence from $10-26 \%[9,36,37]$. Indeed, the largest lesion amenable to en bloc resection with the EMR cap or ligator device is about $15 \mathrm{~mm}$. Conversely, endoscopic submucosal dissection (ESD) allows for en bloc resection of neoplastic lesions irrespective of their size [38] Figure 1. Since 2005, over 15 studies have reported outcomes of ESD for esophageal SCC in more than 700 patients, with en bloc resection rates of $95.1 \%$ and histologically complete resection rates of $89.4 \%$. These results were reproduced in several expert Western centers [39-41]. Complications after esophageal ESD for SCC include bleeding within the first $24 \mathrm{~h}$ in $2.1 \%$ of patients and perforations in $5 \%$, both treated conservatively in the vast majority of cases, while strictures occur in $11.2 \%$, mainly after treatment of lesions exceeding $75 \%$ of the esophageal circumference or extending beyond $\mathrm{m} 2[41,42]$. No procedure-related mortality was reported after ESD or EMR.

No randomized study has compared EMR and ESD. Takahashi et al compared the outcomes of 184 lesions treated by EMR to 116 lesions treated by ESD and found a significantly higher R0 resection rate with ESD (97.4\% vs. $78.3 \%, \mathrm{P}=0.0002)$ and a lower local recurrence rate $(0.9 \%$ vs. $9.8 \%, \mathrm{P}=0.0065$ ) [37]. In addition, Cao et al reported that ESD provided a significantly higher en bloc resection rate than EMR, also for lesions smaller than $10 \mathrm{~mm}$ [43]. These data, along with the optimal histological assessment of the risk of lymph-node involvement allowed by a single large resection specimen, have made ESD the current standard for ER of esophageal SCC [8] (Table 1).

\section{Endoscopic ablation}

Radiofrequency ablation (RFA) probes deliver a $465-\mathrm{kHz}$ energy waveform via a bipolar arrangement of electrodes over a wire-guided balloon or on an articulated over-the-scope distal attachment (HALO system, Medtronics). The safety and efficacy of RFA have been established for the eradication of early neoplasia in Barrett's esophagus in numerous studies, including three randomized controlled trials [47-49]. Thus, RFA has been proposed for flat early squamous neoplasia, including early SCC, with encouraging results, including $84 \%$ complete eradication at 12 months, $2 \%$ neoplastic progression managed endoscopically, and a $20 \%$ stricture rate after a median of 2 RFA sessions [50]. However, endoscopic recognition of T1a m1-2 lesions amenable to RFA, as opposed to deeper lesions requiring ER or surgery because of potential lymph-node metastases, has proven to be difficult, even for expert endoscopists [51]. Furthermore, the costs associated with RFA remain high. Therefore, the use of RFA in early squamous neoplasia is currently not recommended.

Canto et al recently reported the results of balloon-based cryoablation of early squamous neoplasia, including nonneoplastic Lugol-unstained lesions, with a high efficacy at 1 year and a good safety profile [52]. However, as with RFA, the risk of mistaking an invasive SCC for a dysplastic lesion and ablating instead of resecting it is likely to limit the indications of cryoablation or any ablative technique in the squamous epithelium.

\section{Surveillance after resection}

Since ESD has become the standard treatment for superficial SCC, the risk of local recurrence has become virtual in the case of $\mathrm{R} 0$ resection. However, the risk of metachronous cancer in the esophagus reaches $20 \%$ at 5 years [53] and the risk of distant metastases justifies endoscopic surveillance after resection. No prospective, large-scale study has yet assessed the risk of lymph-node metastases in early SCC. In one of the largest reports, which included over 500 early SCCs treated endoscopically and followed over 5 years, the cumulative risk of lymph-node metastases ranged from $0.4 \%$ for $\mathrm{T} 1 \mathrm{a}$ m1-2 SCC, $8.7 \%$ for T1am3, $7.7 \%$ for T1bsm 1 , to $36.2 \%$ for T1bsm2 lesions [53]. These numbers are in line with those reported by other teams, including surgical series, with a $0-2 \%$ risk of lymph-node metastases for T1am1-2 lesions, 8-18\% for lesions invading the muscularis mucosae (m3), and 7.7 to $19 \%$ for lesions invading the submucosa to less than $200 \mu \mathrm{m}$ (sm1), and $30-54 \%$ for $\mathrm{sm} 2$ or sm3 lesions [6-8,53]. These figures have to be interpreted with caution for $\mathrm{m} 3$ and $\mathrm{sm} 1$ lesions, since most of these lesions also have poor qualitative histoprognostic factors, such as poor differentiation or lymphovascular involvement, while well differentiated $\mathrm{m} 3$ or sm1 tumors without these poor histoprognostic factors rarely cause lymph-node metastases [54]. As a result, yearly endoscopic surveillance is recommended after R0 resection of a T1am1-2 SCC. For $\mathrm{m} 3$ or sm1 tumors, the decision is 
Table 1 Outcomes of the main studies comparing endoscopic mucosal resection and endoscopic submucosal dissection for esophageal squamous cell neoplasia

\begin{tabular}{|c|c|c|c|c|c|c|c|c|}
\hline First author & $\begin{array}{l}\text { Number of } \\
\text { patients } \\
(\mathrm{EMR} / \mathrm{ESD})\end{array}$ & $\begin{array}{l}\text { Mean } \\
\text { diameter of } \\
\text { the lesion, } \\
\text { mm } \\
\text { (EMR/ESD) }\end{array}$ & $\begin{array}{l}\text { Mean } \\
\text { procedure } \\
\text { time, min } \\
(\mathrm{EMR} / \mathrm{ESD})\end{array}$ & $\begin{array}{l}\text { R0 resection } \\
(\mathrm{EMR} / \mathrm{ESD})\end{array}$ & $\begin{array}{l}\text { Curative } \\
\text { resection rate } \\
(\mathrm{EMR} / \mathrm{ESD})\end{array}$ & $\begin{array}{c}\text { Early adverse events } \\
\text { (perforation, bleeding) } \\
\quad(\text { EMR/ESD) }\end{array}$ & $\begin{array}{l}\text { Stricture rate } \\
(\mathrm{EMR} / \mathrm{ESD})\end{array}$ & $\begin{array}{c}\text { Recurrent or } \\
\text { metachronous } \\
\text { neoplasia } \\
\text { (EMR/ESD) }\end{array}$ \\
\hline Ishihara [44] & $119 / 29$ & $13 / 16^{*}$ & $18 / 64$ * & NA & $58 \% / 97 \%^{*}$ & $1 \% / 3 \%$ & $3 \% / 0 \%$ & $2 \% / 0 \%$ \\
\hline Takahashi [37] & $184 / 116$ & $20 / 30^{*}$ & $44 / 74^{*}$ & $78 \% / 98 \% *$ & $78 \% / 99 \% *$ & $2 \% / 3 \%$ & $9 \% / 17 \% *$ & $10 \% / 1 \% *$ \\
\hline Urabe [45] & $63 / 59$ & NA & $19 / 50$ & $73 \% / 97 \% *$ & NA & $4 \% / 9 \%$ & $5 \% / 10 \%$ & $9 \% / 0 \%^{*}$ \\
\hline Teoh [46] & $10 / 18$ & $12 / 24^{*}$ & NA & $78 \% / 80 \%$ & NA & $1 \% / 10 \%$ & $0 \% / 11 \%$ & $10 \% / 0 \%$ \\
\hline
\end{tabular}

${ }^{*} P<0.05$ R0, histologically complete resection; NA, not available; EMR, endoscopic mucosal resection; ESD, endoscopic submucosal dissection

made during a multidisciplinary meeting, weighing the risk of lymph-node metastases against the individual assessment of esophagectomy-associated morbidity and mortality. Clearcut follow-up modalities have not been defined, but should probably include an esophagoscopy after 3 months and yearly thereafter, combined with endoscopic ultrasonography and sixmonthly CT scan, as for surgically resected esophageal cancer. For sm 2 or sm 3 tumors, ER is not curative and esophagectomy with lymph-node resection is recommended [8].

In the case of $\mathrm{R} 1$ resection on the horizontal (lateral) margins, recurrences can usually be managed endoscopically and close endoscopic surveillance is recommended [8]. A surveillance protocol with an esophagoscopy every 3 months for 1 year, then yearly, can be considered. Conversely, positive vertical margins suggest deep mural invasion and prompt surgical resection if the patient's clinical status is compatible.

\section{Endoscopic management of adenocarcinoma}

\section{ER}

ER is the first step in the treatment of early adenocarcinoma and Barrett's neoplasia but can also be the last step of the diagnostic workup. The standard EMR technique requires a large straight or oblique cap of $12 \mathrm{~mm}$ inner diameter with a distal ridge, allowing for the placement of an asymmetrical snare after submucosal lifting. Another widely used technique is the multiband EMR technique, which uses a modified variceal band ligator and a 5-7F polypectomy snare. A randomized controlled study comparing both techniques showed that multiband EMR was cheaper and quicker than cap-EMR, but similarly safe, despite the absence of submucosal lifting [55]. In accordance with these data, Alvarez Herrero et $a l$, in a large prospective study including 1060 ER using multiband EMR, recorded no perforations [56], and even larger studies have confirmed the safety and efficacy of EMR for intramucosal EAC [57]. Finally, diagnostic and therapeutic ER using multiband EMR for all visible abnormalities arising on a Barrett's mucosa can be preferred to biopsy sampling in certain cases, especially since biopsies can downgrade EAC to HGD in up to $40 \%$ of cases [8].
In contrast to squamous neoplasia, ESD has not been accepted as the gold standard for Barrett's neoplasia. Indeed, the principle of ESD - allowing for en bloc resection of lesions irrespective of their size, at the cost of longer procedures, and a longer learning curve-is hardly compatible with the extensive and often multifocal nature of Barrett's neoplasia. As a result, prospective studies of ESD for Barrett's neoplasia have shown disappointing results, with $39-74 \%$ histologically complete resection rates for HGD or EAC and 48-96\% curative resection rates for EAC (Table 2). No mortality was associated with ESD for EAC, while 1.1-2.7\% intraprocedural bleeding and 2.3-4\% perforation rates were reported [8]. However, the vast majority of the perforations are diagnosed and closed during the endoscopic procedure and treated conservatively. Although the latest ESGE guidelines recommended that piecemeal ER should be preferred over ESD in most cases [8], the recent development of ESD in western centers that specialize in Barrett's esophagus may change therapeutic paradigms in the near future. Until multicenter prospective studies have further demonstrated its efficacy and superiority over EMR, ESD in Barrett's neoplasia should probably be limited to expert centers and selected cases, such as protruding lesions not amenable to cap or multiband EMR, lesions larger than $15 \mathrm{~mm}$ in size, and poorly lifting lesions or those with a high suspicion of submucosal invasion.

\section{Endoscopic ablation}

\section{RFA}

The first step in the management of a patient with Barrett's neoplasia is an ER of all visible lesions, since they have a probability of harboring HGD or EAC close to 80\% [68]. Complete eradication of the remaining Barrett's mucosa is indicated, because $30 \%$ of the patients will experience a recurrence of neoplasia during follow up [69]. However, circumferential resection of the Barrett's mucosa results in an esophageal stricture in up to $88 \%$ of patients, with a $4 \%$ recurrence rate of neoplasia at 24 months [48]. A randomized study has shown that focal ER, followed by ablation of the remaining Barrett's mucosa, was equally effective and safer compared to stepwise ER [48]. The efficacy of this treatment 
Table 2 Outcomes of the main studies assessing endoscopic submucosal dissection for Barrett's associated neoplasia

\begin{tabular}{|c|c|c|c|c|c|c|c|c|}
\hline First author & $\begin{array}{l}\text { Number } \\
\text { of patients }\end{array}$ & $\begin{array}{c}\text { Mean diameter } \\
\text { of the lesion, } \\
\mathrm{mm}\end{array}$ & $\begin{array}{c}\text { Mean } \\
\text { procedure } \\
\text { time, min }\end{array}$ & $\begin{array}{l}\text { R0 resection } \\
\text { rate for } \\
\text { EAC/HGD }\end{array}$ & $\begin{array}{c}\text { Curative } \\
\text { resection rate } \\
\text { for } \mathrm{EAC} / \mathrm{HGD}\end{array}$ & $\begin{array}{l}\text { Early adverse events } \\
\text { (perforation, bleeding) }\end{array}$ & $\begin{array}{l}\text { Stricture } \\
\text { rate }\end{array}$ & $\begin{array}{c}\text { Recurrent or } \\
\text { metachronous } \\
\text { neoplasia }\end{array}$ \\
\hline Neuhaus [58] & 30 & 20 & 75 & $39 \%$ & $39 \%$ & $4 \%$ & $0 \%$ & $0 \%$ \\
\hline Hoteya [59] & 25 & 20 & 85 & $64 \%$ & $48 \%$ & $20 \%$ & $0 \%$ & $0 \%$ \\
\hline Nagami [60] & 14 & 18 & 85 & $100 \%$ & $85 \%$ & $0 \%$ & $0 \%$ & $0 \%$ \\
\hline Kagemoto [61] & 23 & 19 & 93 & $85 \%$ & $65 \%$ & $4 \%$ & $15 \%$ & $7 \%$ \\
\hline Probst [39] & 87 & 21 & 140 & $74 \%$ & $72 \%$ & $1 \%$ & $9 \%$ & $2 \%$ \\
\hline Chevaux [62] & 75 & 20 & 117 & $64 \%$ & $64 \%$ & $7 \%$ & $60 \%$ & $10 \%$ \\
\hline Höbel [63] & 22 & NA & 114 & $82 \%$ & $77 \%$ & $13 \%$ & $13 \%$ & $6 \%$ \\
\hline Barret [64] & 35 & 50 & 191 & $72 \%$ & $51 \%$ & $8 \%$ & $6 \%$ & $17 \%$ \\
\hline Terheggen [65] & 20 & 30 & 54 & $59 \%$ & $53 \%$ & $10 \%$ & $0 \%$ & $6 \%$ \\
\hline Yang [66] & 46 & 41 & 121 & $76 \%$ & $69 \%$ & $9 \%$ & $15 \%$ & $7 \%$ \\
\hline Subramanian [67] & 124 & 31 & 90 & $79 \%$ & $66 \%$ & $2 \%$ & $2 \%$ & $13 \%$ \\
\hline
\end{tabular}

R0, histologically complete resection; HGD, high-grade dysplasia; EAC, early adenocarcinoma; NA, not available

approach has been confirmed by several larger prospective studies [70,71] that achieved $90 \%$ complete eradication of intestinal metaplasia and neoplasia at 5 years [71]. Finally, EMR of visible lesions and RFA of the remaining Barrett's esophagus is currently the gold standard in the treatment of Barrett's neoplasia Figure 2. This is particularly true for long circumferential Barrett's esophagus, in which other ablative techniques can be time-consuming and less effective.

When HGD is diagnosed on random biopsy samples without any visible lesion to resect, and after confirmation of HGD by an expert pathologist, ablation of the complete Barrett's segment is indicated [32]. Recent international guidelines have recommended offering endoscopic therapy, including ablative therapies, for Barrett's esophagus containing confirmed LGD [32,72]. However, because evidence is supported by only one randomized trial, in which LGD in the surveillance group had an unexpectedly high rate of progression to EAC [49], this recommendation must be treated with caution: as rightfully stated by the Bobcat consortium and ESGE, RFA can be used in Barrett's esophagus with LGD containing high risk features, such as multifocality of LGD, confirmation of LGD by repeat, expert-analyzed biopsies, focal visible lesion or long-segment Barrett's esophagus.

\section{Other techniques}

Argon plasma coagulation (APC) is a widely available and relatively cheap ablative endoscopic therapy for residual Barrett's esophagus. Initial studies demonstrated a reduction in the recurrence rate of neoplasia from $37 \%$ to $3 \%$ at 2 years after ER [73]. However, APC is operator-dependent, timeconsuming (particularly for larger Barrett's segments) and may result in a $9 \%$ stricture rate. A recently developed APC probe allowing for submucosal injection of $0.9 \%$ saline prior to a high-power ablation, called Hybrid-APC ${ }^{\mathrm{m}}$, could improve the safety and efficacy of APC ablation [74].
Finally, balloon based cryoablation has recently been reported as an effective modality for ablating residual Barrett's islands after ER [75]. Studies reporting the outcomes of cryoablation performed on larger Barrett's segments are expected.

\section{Surveillance after resection}

As mentioned above, the risk of local or metachronous recurrence of EAC is largely reduced by the systematic ablation of the residual Barrett's esophagus. However, close endoscopic surveillance and prolonged follow up is still recommended by current guidelines [32].

The risk of lymph-node metastases associated with EAC can be estimated according to quantitative factors, such as the depth of tumor infiltration, and qualitative factors, such as the differentiation grade and the presence of lymphovascular involvement. ER can be considered curative for EAC invading the mucosa or the superficial submucosal up to $500 \mu \mathrm{m}$, provided they are not poorly differentiated and do not show lymphovascular involvement [8]. For these lesions, the risk of lymph-node metastases is below $2 \%$. In the case of deeper infiltration in the submucosa, positive vertical margins, or the presence of poor qualitative histoprognostic features, the risk of lymph-node metastases exceeds $10 \%$ and additional therapy by esophagectomy with lymph-node dissection should be discussed. In the case of positive horizontal margins, additional ER or ablative therapy can be offered.

\section{Surgery}

Surgery has long been the gold standard for the treatment of localized esophageal cancer, including early esophageal cancer. However, esophagectomy results in 2-5\% mortality and $30-40 \%$ severe morbidity, and significantly alters the patients' 
quality of life for at least one year [76-78]. However, surgical resection of a T1 esophageal cancer is associated with an overall 5-year survival of $77-88 \%$, with a $19-43 \%$ 5-year risk of tumor recurrence [79-81]. Comparison of the outcomes of surgical and ER treatment lacks well designed prospective studies. Most data pertain to EAC, and in the only large cohort including SCC patients both treatment groups were hardly comparable, with over three times more T1b lesions in the surgery group [81]. All studies resulted in comparable oncological outcomes, with greater postprocedural mortality and morbidity induced by surgery $[13,81,82]$. As expected, higher local recurrence rates and metachronous lesions were observed in the endoscopically treated patient groups, but all of these were managed endoscopically with no impact on survival. As a conclusion, ER seems preferable to surgery as a first-line treatment approach for early esophageal neoplasia. ER is an optimal staging procedure for all T1 lesions, a curative treatment for the vast majority of T1a lesions, and a potentially curative treatment for T1b lesions with superficial invasion of the submucosa or in patients with high operative risk.

\section{Chemoradiotherapy (CRT)}

CRT and surgery have comparable efficacy in the treatment of locally advanced esophageal cancer [83]. Therefore, several teams have assessed CRT alone for early esophageal neoplasia. Protocols are usually the same as for advanced esophageal cancer and typically involve 45 to 50 Gy external beam radiotherapy over a 5-week period and 2 cycles of chemotherapy based on cisplatin and 5-fluorouracil.

CRT alone was also studied for early esophageal cancers: in a study involving 37 stage I esophageal cancer, of which 30 were $\mathrm{T} 1 \mathrm{~b}$ lesions, Jingu et al reported a poor cancer-specific survival rate of $87.6 \%$ at 5 years [84]. In a larger study that included 72 patients with T1 esophageal cancer treated by CRT alone, Kato et al found $68.1 \%$ 4-year recurrencefree survival, excluding local $15 \%$ lesions recurring locally and treated by ER [85]. Nemoto et al, in a large multicenter study that included 141 patients with T1 esophageal cancers treated by CRT or radiotherapy alone, found a 3-year overall survival of $90 \%$ and $70 \%$ for patients with T1a and T1b lesions, respectively, and better outcomes with CRT compared with radiotherapy alone [86]. However, it has to be noted that the treatment regimens were extremely heterogeneous in terms of radiotherapy dose and type, and the administration of chemotherapy concurrent with radiotherapy. The combination of external-beam radiotherapy and high dose brachytherapy for superficial esophageal cancer has also been reported outside Japan, in 66 patients with T1 esophageal cancers, with 5 -year relapse-free survival and cause-specific survival of $54.6 \%$ and $76.9 \%$ [87]. Finally, the quality of the data on CRT for the treatment of superficial esophageal cancer is currently insufficient to draw definitive conclusions. Available data suggest that CRT, possibly including brachytherapy as an adjunct to external-beam radiotherapy, is feasible and safe in inoperable patients. However, the relapse-free and cause- specific survival rates are far below those of surgery or ER. Furthermore, although ER remains feasible after CRT, the curative resection rates barely exceed $50 \%$ and the complication rate is unusually high, mainly because of a higher occurrence of esophageal strictures [88].

A promising role for CRT could be to replace surgical resection after non-curative ER. This treatment strategy, however, already recommended in the ESGE guidelines and performed in expert centers, relies only on small retrospective case series [89-91].

\section{Perspectives}

\section{Diagnosis}

Currently, the indication for ER relies on a fine endoscopic assessment of mucosal anomalies, and the prediction of the malignant potential is based on architectural features and the presence of dysplasia on histology. The detection of molecular alterations of the Barrett's epithelium could be a useful tool for risk stratification and prediction of response to therapy. For example, p53 aberrant expression (either absent or overexpression) detected by immunohistochemistry has been extensively studied, and could be as discriminative as the presence of LGD in the prediction of neoplastic progression [92,93]. Furthermore, analysis of the p53 expression pattern could help in improving the diagnostic accuracy of esophageal biopsies and lowering the rate of "indefinite for dysplasia" [94]. Specific genetic alterations of the MYC, $p 16$, Her-2/neu, or ZNF217 genes, detected by fluorescence in situ hybridization on cytological brush samples, are associated with a lower rate of response to endoscopic therapy [95]. The recent development of a transoral brush cytology device that allows for RNA extraction and diagnosis by microarray, and quantitative polymerase chain reaction testing for specific genetic biomarkers of Barrett's esophagus and early neoplastic changes, might lead clinicians in the future to switch from endoscopic examination and quadrantic biopsies to transoral unsedated cytological brushing of the entire Barrett's segment. This might help first to overcome the sampling bias; second to assess the genetic diversity among Barrett's cells, better predict their malignant potential and determine tailored surveillance intervals; and finally to detect molecular changes prompting ER or ablation, before any macroscopic or microscopic change can be seen $[96,97]$.

\section{Treatment}

Although ablative therapies offer a safe treatment modality for residual Barrett's esophagus, their application for early squamous cell neoplasia is limited, their long-term efficacy is unknown, and their costs are high. Therefore, epitheliumregenerating, anti-inflammatory or antifibrotic drugs or devices are under development in order to prevent post-endoscopic esophageal stricture, and possibly allow for a single-step ER 


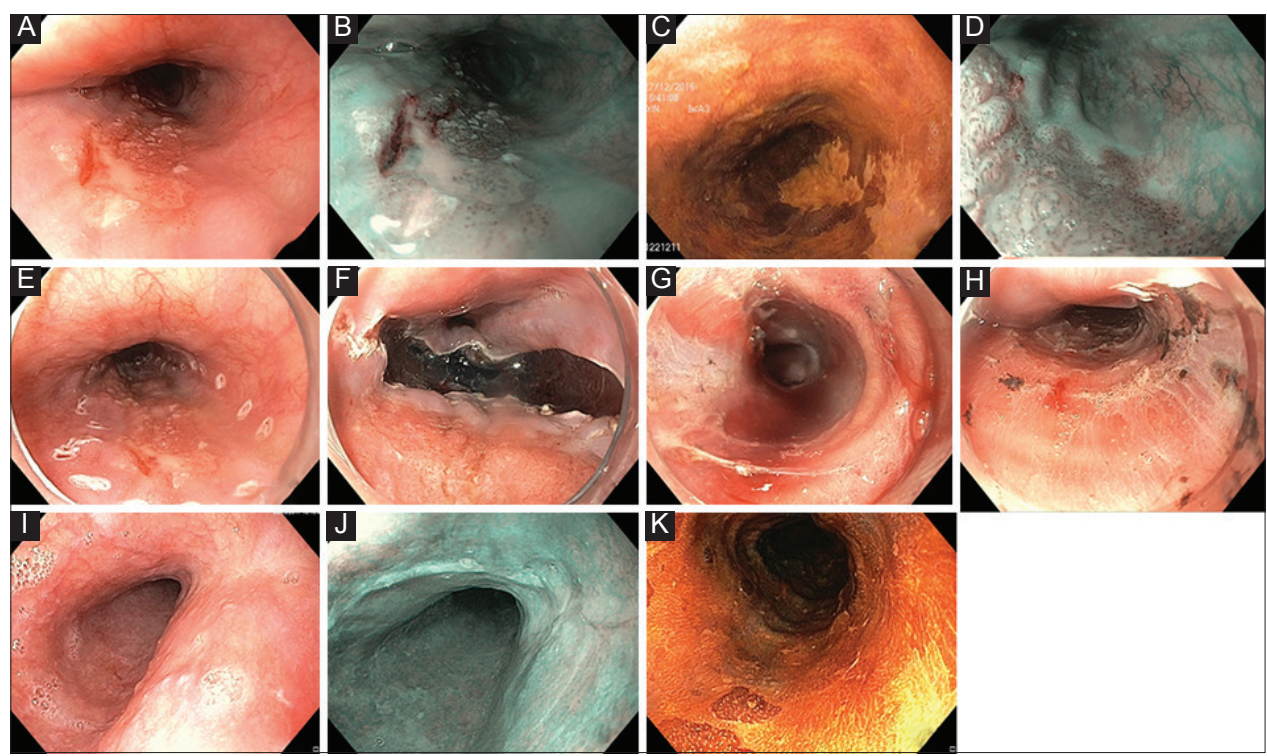

Figure 1 Endoscopic submucosal dissection of an early squamous cell carcinoma (T1am2). (A) High-definition white-light endoscopy visualization of a Paris 0-IIb lesion of the mid esophagus. (B) Narrow-band imaging and (C) Lugol coloration showing the limits of the lesion. (D) Narrow-band imaging with magnification showing the type V-2 intrapapillary capillary loops suggesting $\mathrm{m} 2$, resectable lesion. (E) Circular markings before endoscopic submucosal dissection. (F) Distal incision. (G) Submucosal dissection using the tunnel technique under the lesion. (H) Resection wound after en bloc endoscopic submucosal dissection. (I, J, K) Three-month follow-up endoscopy showing a clean esophageal, Lugol-negative scar, without evidence for recurrence or residual neoplasia
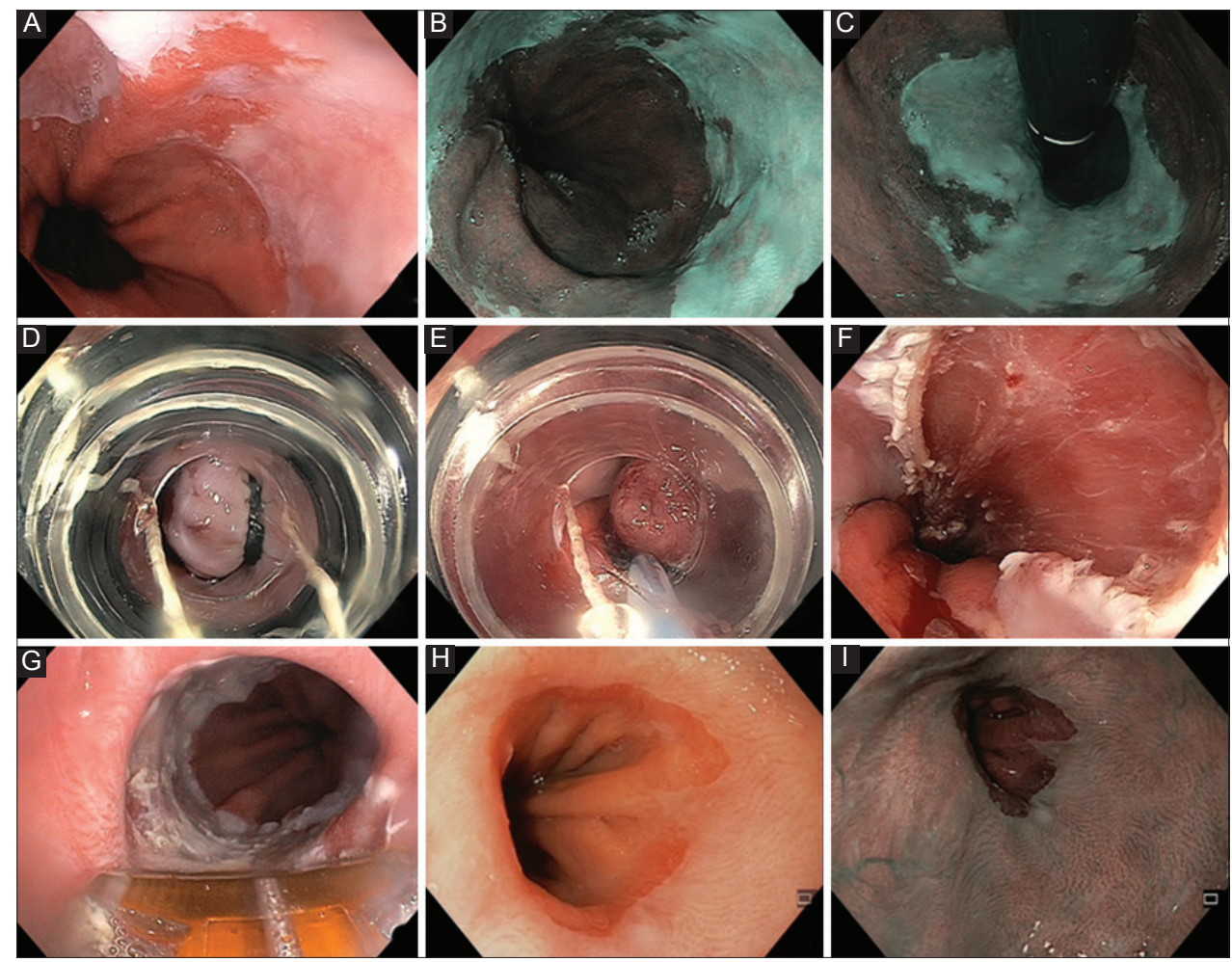

Figure 2 Endoscopic treatment of early Barrett's neoplasia (T1am1). (A) High-definition white-light endoscopy showing a visible abnormality with nodularity and irregular nodularity and irregular pit pattern on a short Barrett's tongue. (B and C) Narrow-band imaging of the lesion in direct and retroflex view. (D) Band ligation of the lesion without submucosal lifting, before (E) placement of the snare below the band, and (F) resection wound after multiband mucosectomy. $(G)$ Radiofrequency ablation using a focal probe to ablate residual Barrett's esophagus, 3 months after endoscopic mucosal resection. (H and I) Follow-up endoscopy 3 months later, showing a normal-appearing neo-Z line under white-light endoscopy $(\mathrm{H})$ and narrow-band imaging (I) 
of large esophageal neoplasms or of the complete Barrett's esophagus [11].

Finally, the surgical risk of esophagectomy in the case of noncurative ER for a superficial esophageal cancer may be excessive for frail or elderly patients, or patients with a low risk of lymphnode metastases: therefore, alternatives to surgical resection, such as esophagus-preserving lymphadenectomy [98] or "adjuvant" chemoradiotherapy, are under study [89-91].

\section{Concluding remarks}

Endoscopy allows for the screening, early diagnosis, treatment and follow-up of superficial esophageal cancer. In squamous cell neoplasia, endoscopic therapy consists in ESD, while EMR followed by the ablation of the remaining Barrett's esophagus remains the recommended treatment approach for early adenocarcinoma. Optimal surveillance modalities after ER are still to be determined. The need for trained endoscopists, expert pathologists, and dedicated multidisciplinary meetings underlines the role of expert centers in this pathology.

\section{References}

1. Ferlay J, Soerjomataram I, Dikshit R, et al. Cancer incidence and mortality worldwide: sources, methods and major patterns in GLOBOCAN 2012. Int J Cancer 2015;136:E359-E386.

2. Arnold M, Soerjomataram I, Ferlay J, Forman D. Global incidence of oesophageal cancer by histological subtype in 2012. Gut 2015;64:381-387.

3. Prabhu A, Obi KO, Rubenstein JH. Systematic review with metaanalysis: race-specific effects of alcohol and tobacco on the risk of oesophageal squamous cell carcinoma. Aliment Pharmacol Ther 2013;38:1145-1155.

4. Pohl H, Welch HG. The role of overdiagnosis and reclassification in the marked increase of esophageal adenocarcinoma incidence. J Natl Cancer Inst 2005;97:142-146.

5. Lepage C, Rachet B, Jooste V, Faivre J, Coleman MP. Continuing rapid increase in esophageal adenocarcinoma in England and Wales. Am J Gastroenterol 2008;103:2694-2699.

6. Endoscopic Classification Review Group. Update on the Paris classification of superficial neoplastic lesions in the digestive tract. Endoscopy 2005;37:570-578.

7. The Paris endoscopic classification of superficial neoplastic lesions. esophagus, stomach, and colon. Gastrointest Endosc 2003;58(6 Suppl):S3-S43.

8. Pimentel-Nunes P, Dinis-Ribeiro M, Ponchon T, et al. Endoscopic submucosal dissection: European Society of Gastrointestinal Endoscopy (ESGE) Guideline. Endoscopy 2015;47:829-854.

9. Katada C, Muto M, Manabe T, Boku N, Ohtsu A, Yoshida S. Esophageal stenosis after endoscopic mucosal resection of superficial esophageal lesions. Gastrointest Endosc 2003;57:165-169.

10. Takahashi H, Arimura Y, Okahara S, et al. Risk of perforation during dilation for esophageal strictures after endoscopic resection in patients with early squamous cell carcinoma. Endoscopy 2011;43:184-189.

11. Barret M, Beye B, Leblanc S, et al. Systematic review: the prevention of oesophageal stricture after endoscopic resection. Aliment Pharmacol Ther 2015;42:20-39.
12. Zehetner J, DeMeester SR, Hagen JA, et al. Endoscopic resection and ablation versus esophagectomy for high-grade dysplasia and intramucosal adenocarcinoma. I Thorac Cardiovasc Surg 2011;141:39-47.

13. Pech O, Bollschweiler E, Manner H, Leers J, Ell C, Hölscher AH. Comparison between endoscopic and surgical resection of mucosal esophageal adenocarcinoma in Barrett's esophagus at two high-volume centers. Ann Surg 2011;254:67-72.

14. Gupta N, Gaddam S, Wani SB, Bansal A, Rastogi A, Sharma P. Longer inspection time is associated with increased detection of high-grade dysplasia and esophageal adenocarcinoma in Barrett's esophagus. Gastrointest Endosc 2012;76:531-538.

15. Sharma P, Dent J, Armstrong D, et al. The development and validation of an endoscopic grading system for Barrett's esophagus: the Prague C \& M criteria. Gastroenterology 2006;131:1392-1399.

16. Morita FH, Bernardo WM, Ide E, et al. Narrow band imaging versus lugol chromoendoscopy to diagnose squamous cell carcinoma of the esophagus: a systematic review and meta-analysis. BMC Cancer 2017;17:54.

17. Inoue $H$, Kaga $M$, Ikeda $H$, et al. Magnification endoscopy in esophageal squamous cell carcinoma: a review of the intrapapillary capillary loop classification. Ann Gastroenterol 2015;28:41-48.

18. Ngamruengphong S, Sharma VK, Das A. Diagnostic yield of methylene blue chromoendoscopy for detecting specialized intestinal metaplasia and dysplasia in Barrett's esophagus: a metaanalysis. Gastrointest Endosc 2009;69:1021-1028.

19. Kara MA, Peters FP, Rosmolen WD, et al. High-resolution endoscopy plus chromoendoscopy or narrow-band imaging in Barrett's esophagus: a prospective randomized crossover study. Endoscopy 2005;37:929-936.

20. Longcroft-Wheaton G, Duku M, Mead R, Poller D, Bhandari P. Acetic acid spray is an effective tool for the endoscopic detection of neoplasia in patients with Barrett's esophagus. Clin Gastroenterol Hepatol 2010;8:843-847.

21. Curvers W, Baak L, Kiesslich R, et al. Chromoendoscopy and narrow-band imaging compared with high-resolution magnification endoscopy in Barrett's esophagus. Gastroenterology 2008;134:670-679.

22. Mannath J, Subramanian V, Hawkey CJ, Ragunath K. Narrow band imaging for characterization of high grade dysplasia and specialized intestinal metaplasia in Barrett's esophagus: a metaanalysis. Endoscopy 2010;42:351-359.

23. Sharma P, Bergman JJ, Goda K, et al. Development and validation of a classification system to identify high-grade dysplasia and esophageal adenocarcinoma in Barrett's esophagus using narrowband imaging. Gastroenterology 2016;150:591-598.

24. Thosani N, Singh H, Kapadia A, et al. Diagnostic accuracy of EUS in differentiating mucosal versus submucosal invasion of superficial esophageal cancers: a systematic review and metaanalysis. Gastrointest Endosc 2012;75:242-253.

25. Sgourakis G, Gockel I, Lyros O, Hansen T, Mildenberger P, Lang H. Detection of lymph node metastases in esophageal cancer. Expert Rev Anticancer Ther 2011;11:601-612.

26. Pech O, May A, Günter E, Gossner L, Ell C. The impact of endoscopic ultrasound and computed tomography on the TNM staging of early cancer in Barrett's esophagus. Am J Gastroenterol 2006;101:2223-2229.

27. Klapman J, Chang KJ, Wiersema M, Murata Y, Vilmann P. Endoscopic ultrasound-guided fine-needle aspiration biopsy in esophageal cancer. Endoscopy 2005;37:381-385.

28. Pouw RE, Heldoorn N, Alvarez Herrero L, et al. Do we still need EUS in the workup of patients with early esophageal neoplasia? A retrospective analysis of 131 cases. Gastrointest Endosc 2011;73:662-668.

29. Boerwinkel DF, Shariff MK, di Pietro M, et al. Fluorescence imaging for the detection of early neoplasia in Barrett's esophagus: old looks 
or new vision? Eur J Gastroenterol Hepatol 2014;26:691-698.

30. Boerwinkel DF, Swager A, Curvers WL, Bergman JJ. The clinical consequences of advanced imaging techniques in Barrett's esophagus. Gastroenterology 2014;146:622-629.

31. Swager AF, Tearney GJ, Leggett CL, et al. Identification of volumetric laser endomicroscopy features predictive for early neoplasia in Barrett's esophagus using high-quality histological correlation. Gastrointest Endosc 2017;85:918-926.e7.

32. Shaheen NJ, Falk GW, Iyer PG, Gerson LB; American College of Gastroenterology. ACG Clinical Guideline: Diagnosis and management of Barrett's esophagus. Am J Gastroenterol 2016;111:30-50.

33. Inoue H, Endo M. Endoscopic esophageal mucosal resection using a transparent tube. Surg Endosc 1990;4:198-201.

34. Soehendra N, Seewald S, Groth S, et al. Use of modified multiband ligator facilitates circumferential EMR in Barrett's esophagus (with video). Gastrointest Endosc 2006;63:847-852.

35. Zhang YM, Boerwinkel DF, Qin X, et al. A randomized trial comparing multiband mucosectomy and cap-assisted endoscopic resection for endoscopic piecemeal resection of early squamous neoplasia of the esophagus. Endoscopy 2016;48:330-338.

36. Pech O, Gossner L, Manner H, et al. Prospective evaluation of the macroscopic types and location of early Barrett's neoplasia in 380 lesions. Endoscopy 2007;39:588-593.

37. Takahashi H, Arimura Y, Masao H, et al. Endoscopic submucosal dissection is superior to conventional endoscopic resection as a curative treatment for early squamous cell carcinoma of the esophagus (with video). Gastrointest Endosc 2010;72:255-264, 264. e1-e2.

38. Yamamoto H, Kawata H, Sunada K, et al. Successful en-bloc resection of large superficial tumors in the stomach and colon using sodium hyaluronate and small-caliber-tip transparent hood. Endoscopy 2003;35:690-694.

39. Probst A, Aust D, Märkl B, Anthuber M, Messmann H. Early esophageal cancer in Europe: endoscopic treatment by endoscopic submucosal dissection. Endoscopy 2015;47:113-121.

40. Repici A, Hassan C, Carlino A, et al. Endoscopic submucosal dissection in patients with early esophageal squamous cell carcinoma: results from a prospective Western series. Gastrointest Endosc 2010;71:715-721.

41. Kim JS, Kim BW, Shin IS. Efficacy and safety of endoscopic submucosal dissection for superficial squamous esophageal neoplasia: a meta-analysis. Dig Dis Sci 2014;59:1862-1869.

42. Ono S, Fujishiro M, Niimi K, et al. Predictors of postoperative stricture after esophageal endoscopic submucosal dissection for superficial squamous cell neoplasms. Endoscopy 2009;41:661-665.

43. Cao Y, Liao C, Tan A, Gao Y, Mo Z, Gao F. Meta-analysis of endoscopic submucosal dissection versus endoscopic mucosal resection for tumors of the gastrointestinal tract. Endoscopy 2009;41:751-757.

44. Ishihara $\mathrm{R}$, Iishi $\mathrm{H}$, Uedo $\mathrm{N}$, et al. Comparison of EMR and endoscopic submucosal dissection for en bloc resection of early esophageal cancers in Japan. Gastrointest Endosc 2008;68:1066-1072.

45. Urabe Y, Hiyama T, Tanaka S, Yoshihara M, Arihiro K, Chayama K. Advantages of endoscopic submucosal dissection versus endoscopic oblique aspiration mucosectomy for superficial esophageal tumors. J Gastroenterol Hepatol 2011;26:275-280.

46. Teoh AY, Chiu PW, Yu Ngo DK, Wong SK, Lau JY, Ng EK. Outcomes of endoscopic submucosal dissection versus endoscopic mucosal resection in management of superficial squamous esophageal neoplasms outside Japan. J Clin Gastroenterol 2010;44:e190-e194.

47. Shaheen NJ, Sharma P, Overholt BF, et al. Radiofrequency ablation in Barrett's esophagus with dysplasia. $N$ Engl J Med 2009;360:2277-2288.

48. van Vilsteren FG, Pouw RE, Seewald S, et al. Stepwise radical endoscopic resection versus radiofrequency ablation for Barrett's oesophagus with high-grade dysplasia or early cancer: a multicentre randomised trial. Gut 2011;60:765-773.

49. Phoa KN, van Vilsteren FG, Weusten BL, et al. Radiofrequency ablation vs endoscopic surveillance for patients with Barrett esophagus and low-grade dysplasia: a randomized clinical trial. JAMA 2014;311:1209-1217.

50. He S, Bergman J, Zhang Y, et al. Endoscopic radiofrequency ablation for early esophageal squamous cell neoplasia: report of safety and effectiveness from a large prospective trial. Endoscopy 2015;47:398-408.

51. Jansen M, Schölvinck DW, Kushima R, et al. Is it justified to ablate flat-type esophageal squamous cancer? An analysis of endoscopic submucosal dissection specimens of lesions meeting the selection criteria of radiofrequency studies. Gastrointest Endosc 2014;80:995-1002.

52. Canto MI, Abrams J, Kunzli H, et al. Nitrous oxide cryotherapy for treatment of esophageal squamous cell neoplasia: initial multicenter international experience with a novel portable cryoballoon ablation system (with video). Gastrointest Endosc 2017;87:574-581.

53. Yamashina T, Ishihara R, Nagai K, et al. Long-term outcome and metastatic risk after endoscopic resection of superficial esophageal squamous cell carcinoma. Am J Gastroenterol 2013;108:544-551.

54. Moriya H, Ohbu M, Kobayashi N, et al. Lymphatic tumor emboli detected by $\mathrm{D} 2-40$ immunostaining can more accurately predict lymph-node metastasis. World J Surg 2011;35:2031-2037.

55. Pouw RE, van Vilsteren FG, Peters FP, et al. Randomized trial on endoscopic resection-cap versus multiband mucosectomy for piecemeal endoscopic resection of early Barrett's neoplasia. Gastrointest Endosc 2011;74:35-43.

56. Alvarez Herrero L, Pouw RE, van Vilsteren FG, et al. Safety and efficacy of multiband mucosectomy in 1060 resections in Barrett's esophagus. Endoscopy 2011;43:177-183.

57. Pech O, May A, Manner H, et al. Long-term efficacy and safety of endoscopic resection for patients with mucosal adenocarcinoma of the esophagus. Gastroenterology 2014;146:652-660.e1.

58. Neuhaus H, Terheggen G, Rutz EM, Vieth M, Schumacher B. Endoscopic submucosal dissection plus radiofrequency ablation of neoplastic Barrett's esophagus. Endoscopy 2012;44:1105-1113.

59. Hoteya S, Matsui A, Iizuka T, et al. Comparison of the clinicopathological characteristics and results of endoscopic submucosal dissection for esophagogastric junction and nonjunctional cancers. Digestion 2013;87:29-33.

60. Nagami Y, Machida H, Shiba M, et al. Clinical efficacy of endoscopic submucosal dissection for adenocarcinomas of the esophagogastric junction. Endosc Int Open 2014;2:E15-E20.

61. Kagemoto K, Oka S, Tanaka S, et al. Clinical outcomes of endoscopic submucosal dissection for superficial Barrett's adenocarcinoma. Gastrointest Endosc 2014;80:239-245.

62. Chevaux JB, Piessevaux H, Jouret-Mourin A, Yeung R, Danse E, Deprez PH. Clinical outcome in patients treated with endoscopic submucosal dissection for superficial Barrett's neoplasia. Endoscopy 2015;47:103-112.

63. Höbel S, Dautel P, Baumbach R, et al. Single center experience of endoscopic submucosal dissection (ESD) in early Barrett's adenocarcinoma. Surg Endosc 2015;29:1591-1597.

64. Barret M, Cao DT, Beuvon F, et al. Endoscopic submucosal dissection for early Barrett's neoplasia. United European Gastroenterol J 2016;4:207-215.

65. Terheggen G, Horn EM, Vieth M, et al. A randomised trial of endoscopic submucosal dissection versus endoscopic mucosal resection for early Barrett's neoplasia. Gut 2017;66:783-793.

66. Yang D, Coman RM, Kahaleh M, et al. Endoscopic submucosal dissection for Barrett's early neoplasia: a multicenter study in the United States. Gastrointest Endosc 2017;86:600-607.

67. Subramaniam S, Chedgy F, Longcroft-Wheaton G, et al. Complex 
early Barrett's neoplasia at 3 Western centers: European Barrett's Endoscopic Submucosal Dissection Trial (E-BEST). Gastrointest Endosc 2017;86:608-618.

68. Tharavej C, Hagen JA, Peters JH, et al. Predictive factors of coexisting cancer in Barrett's high-grade dysplasia. Surg Endosc 2006;20:439-443.

69. May A, Gossner L, Pech O, et al. Local endoscopic therapy for intraepithelial high-grade neoplasia and early adenocarcinoma in Barrett's oesophagus: acute-phase and intermediate results of a new treatment approach. Eur J Gastroenterol Hepatol 2002;14:1085-1091.

70. Phoa KN, Pouw RE, van Vilsteren FG, et al. Remission of Barrett's esophagus with early neoplasia 5 years after radiofrequency ablation with endoscopic resection: a Netherlands cohort study. Gastroenterology 2013;145:96-104.

71. Phoa KN, Pouw RE, Bisschops R, et al. Multimodality endoscopic eradication for neoplastic Barrett oesophagus: results of an European multicentre study (EURO-II). Gut 2016;65:555-562.

72. Weusten B, Bisschops R, Coron E, et al. Endoscopic management of Barrett's esophagus: European Society of Gastrointestinal Endoscopy (ESGE) Position Statement. Endoscopy 2017;49:191-198.

73. Manner H, Rabenstein T, Pech O, et al. Ablation of residual Barrett's epithelium after endoscopic resection: a randomized longterm follow-up study of argon plasma coagulation vs. surveillance (APE study). Endoscopy 2014;46:6-12.

74. Manner H, May A, Kouti I, Pech O, Vieth M, Ell C. Efficacy and safety of Hybrid-APC for the ablation of Barrett's esophagus. Surg Endosc 2016;30:1364-1370.

75. Künzli HT, Schölvinck DW, Meijer SL, Seldenrijk KA, Bergman JGHM, Weusten BLAM. Efficacy of the CryoBalloon Focal Ablation System for the eradication of dysplastic Barrett's esophagus islands. Endoscopy 2017;49:169-175.

76. McMillan RR, Berger A, Sima CS, et al. Thirty-day mortality underestimates the risk of early death after major resections for thoracic malignancies. Ann Thorac Surg 2014;98:1769-1774; discussion 1774-1775.

77. Takeuchi H, Miyata H, Gotoh $\mathrm{M}$, et al. A risk model for esophagectomy using data of 5354 patients included in a Japanese nationwide web-based database. Ann Surg 2014;260:259-266.

78. Pennathur A, Gibson MK, Jobe BA, Luketich JD. Oesophageal carcinoma. Lancet 2013;381:400-412.

79. Mariette C, Balon JM, Piessen G, Fabre S, Van Seuningen I, Triboulet JP. Pattern of recurrence following complete resection of esophageal carcinoma and factors predictive of recurrent disease. Cancer 2003;97:1616-1623.

80. Tanaka T, Matono S, Mori N, Shirouzu K, Fujita H. T1 squamous cell carcinoma of the esophagus: long-term outcomes and prognostic factors after esophagectomy. Ann Surg Oncol 2014;21:932-938.

81. Das A, Singh V, Fleischer DE, Sharma VK. A comparison of endoscopic treatment and surgery in early esophageal cancer: an analysis of surveillance epidemiology and end results data. Am J Gastroenterol 2008;103:1340-1345.

82. Prasad GA, Wu TT, Wigle DA, et al. Endoscopic and surgical treatment of mucosal (Tla) esophageal adenocarcinoma in Barrett's esophagus. Gastroenterology 2009;137:815-823.

83. Best LM, Mughal M, Gurusamy KS. Non-surgical versus surgical treatment for oesophageal cancer. Cochrane Database Syst Rev 2016;3:CD011498.

84. Jingu K, Matsushita H, Takeda K, et al. Results of chemoradiotherapy for stage I esophageal cancer in medically inoperable patients compared with results in operable patients. Dis Esophagus 2013;26:522-527.

85. Kato H, Sato A, Fukuda $H$, et al. A phase II trial of chemoradiotherapy for stage I esophageal squamous cell carcinoma: Japan Clinical Oncology Group Study (JCOG9708). Jpn J Clin Oncol 2009;39:638-643.

86. Nemoto K, Yamada S, Nishio M, et al; JASTRO Study Group. Results of radiation therapy for superficial esophageal cancer using the standard radiotherapy method recommended by the Japanese Society of Therapeutic Radiology and Oncology (JASTRO) Study Group. Anticancer Res 2006;26:1507-1512.

87. Pasquier D, Mirabel X, Adenis A, et al. External beam radiation therapy followed by high-dose-rate brachytherapy for inoperable superficial esophageal carcinoma. Int J Radiat Oncol Biol Phys 2006;65:1456-1461.

88. Kondo S, Tajika M, Tanaka T, et al. Prognostic factors for salvage endoscopic resection for esophageal squamous cell carcinoma after chemoradiotherapy or radiotherapy alone. Endosc Int Open 2016;4:E841-E848

89. Kawaguchi G, Sasamoto R, Abe E, et al. The effectiveness of endoscopic submucosal dissection followed by chemoradiotherapy for superficial esophageal cancer. Radiat Oncol 2015;10:31.

90. Mochizuki Y, Saito Y, Tsujikawa T, Fujiyama Y, Andoh A. Combination of endoscopic submucosal dissection and chemoradiation therapy for superficial esophageal squamous cell carcinoma with submucosal invasion. Exp Ther Med 2011;2:1065-1068.

91. Shimizu Y, Kato M, Yamamoto J, et al. EMR combined with chemoradiotherapy: a novel treatment for superficial esophageal squamous-cell carcinoma. Gastrointest Endosc 2004;59:199-204.

92. Kastelein F, Biermann K, Steyerberg EW, et al; ProBar-study group. Aberrant p53 protein expression is associated with an increased risk of neoplastic progression in patients with Barrett's oesophagus. Gut 2013;62:1676-1683.

93. Janmaat VT, van Olphen SH, Biermann KE, Looijenga LHJ, Bruno MB, Spaander MCW. Use of immunohistochemical biomarkers as independent predictor of neoplastic progression in Barrett's oesophagus surveillance: a systematic review and metaanalysis. PLoS One 2017;12:e0186305.

94. van der Wel MJ, Duits LC, Pouw RE, et al. Improved diagnostic stratification of digitised Barrett's oesophagus biopsies by TP53 immunohistochemical staining. Histopathology 2018 Jan 3. [Epub ahead of print] doi: 10.1111/his.13462

95. Timmer MR, Brankley SM, Gorospe EC, et al. Prediction of response to endoscopic therapy of Barrett's dysplasia by using genetic biomarkers. Gastrointest Endosc 2014;80:984-991.

96. Martinez P, Timmer MR, Lau CT, et al. Dynamic clonal equilibrium and predetermined cancer risk in Barrett's oesophagus. Nat Commun 2016;7:12158.

97. Ross-Innes CS, Debiram-Beecham I, O'Donovan M, et al; BEST2 Study Group. Evaluation of a minimally invasive cell sampling device coupled with assessment of trefoil factor 3 expression for diagnosing Barrett's esophagus: a multi-center case-control study. PLoS Med 2015;12:e1001780.

98. Künzli HT, van Berge Henegouwen M, Gisbertz S, et al. Thoracolaparoscopic dissection of esophageal lymph nodes without esophagectomy is feasible in human cadavers and safe in a porcine survival study. Dis Esophagus 2016;29:649-655. 